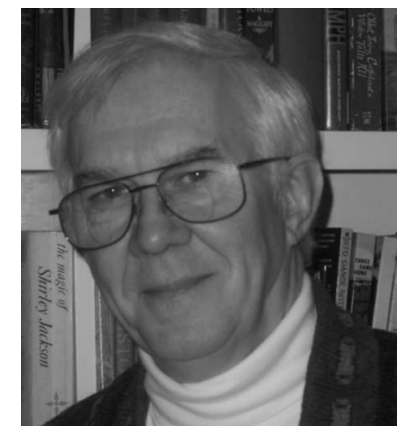

\section{Covering Ground}

In my January editorial, "Shifting Ground," I commented on trends in technology that are affecting the way we gain access to information. A recent trip provided another demonstration of how technology is changing our needs and expectations in travel. We have embraced it wholeheartedly.

During the 1985-86 academic year, I took a sabbatical from the School of Physics at Georgia Tech and spent it at the Optical Sciences Center at the University of Arizona at the invitation of Bob Shannon. While I was there I assembled a bibliography on optomechanical design that became the basis for a volume in the SPIE Milestone Series (Vol. MS-770) and taught (really, produced) a course on optomechanical design with lectures by Bob Hopkins from Rochester and a host of local talent. I accomplished good deal during that academic year and managed to dabble in scanning tunneling microscopy during its early days.

During spring break, Helen and our two youngest children, Sheila and Patrick, flew out for a visit and to do some sightseeing. In the time we had available we visited the Grand Canyon and Canyon de Chelly in the Volkswagen Rabbit that I drove out at the beginning of the sabbatical. At that time, information on touring Arizona was limited. Most of ours came from AAA Tour Books.

This January, Helen and I began a two-week trip at Photonics West. I participated in meetings of SPIE's Information Technology and Publications committees and spent some time in the exhibition halls. The other end of our trip was marked by a talk at the College of Optical Sciences (COS) at Arizona followed some time at the Tucson Gem Show. The Gem Show takes over Tucson in the same way that a major sporting event like the Super Bowl dominates a city... and it lasts for two weeks.

In between these two sets of events, we were free to do whatever we wished. So we flew from San Jose to Tucson to see some sights that were beyond our reach 20 years ago. This time we availed ourselves of a number of advances in travel. To start, we used the Web to investigate possible sites to visit. As a backup I went to AAA and got a set of maps of the Southwest states and the correspond- ing Tour Books. We picked up an SUV, reserved via the Web, at the Tucson airport and headed north. To assist us on the road we brought along a Garmin GPS navigator, which proved both valuable and a great source of entertainment. After a while, we couldn't help but talk back to the device which (who?) we have named Garmine (Jarmeen). In a nicely modulated voice, she described each change in our course about a half mile before it occurred and then when we were supposed to make the turn. When we didn't follow directions, there would be a pause, followed by Garmine's slightly perturbed "Recalculating..."

At times returning to print is useful. Anyone who thinks that any screen-based information system can supplant maps and books must ignore the ease with which these compact items can be rapidly scanned compared to small GPS windows and modest-sized laptop screens. The books and maps together with the help of our cell phones allowed us to pick a few hotels in the area at which we intended to stop and call ahead for a room. This same arrangement got us reservations at restaurants.

Unless there was high-speed Internet at the hotel we wouldn't consider staying there. We required access not just for e-mail but also for weather, planning, and directions. This was particularly true for winter travel in the southern Rockies. But there is a question of coverage. In a few places, like the Fairmont Hotel in San Jose, connections could be made anywhere in the room and in the conference rooms. In Phoenix, my signal died 50 feet beyond the front door. Just outside Bryce Canyon the signal came and went fitfully. I sympathize with the hotel staff, most of them unfamiliar with routers and bandwidth, who must wrestle with a service that they cannot easily produce or improve. It's not the same as sending a set of towels to Room 205.

This new technology shows its limitations. Our cell phones were reduced to doorstops in the vicinity of Bryce and Zion. Although the Garmin provided clear directions most of the time, there were instances when it tried to direct us along unpaved roads or ranch roads. So, we used our devices of near-magic with a mixture of skepticism and awe.

Still, we were able to find a church in Flagstaff before traveling to Zion. While we were in the park we entered 
its address and determined if we left right then we would be able to attend Mass that evening. As it turned out, even with the usual stops, we arrived with a half hour to spare. That time was used to set up our hotel and restaurant for later. With the help of our cell phones we were able to visit Art and Joan Guenther in Albuquerque, while Art was recovering from surgery, and during the stop have dinner with John Shelnutt, one of my first PhDs. In Tucson we stayed in touch with Jose Sasian, my colleague and host at the COS. And along with all this, in our hotel in Tucson we were still able to go to abc.com using Firefox on my MacBook Pro and catch the latest episode of "Ugly Betty," which we had missed during our travels.
By the time we tucked Garmine into her case when we unloaded the rental car, we had managed in 10 days to travel 2000 miles, visit four national parks and a desert museum, catch up with friends in Albuquerque and Tucson, give a talk at COS, and visit the Tucson Gem Show. With new technology, covering ground for today's retirees is a lot easier than it was when they were parents twenty years ago.

Donald C. O'Shea Editor 